\title{
Mechanical and thermal behavior of non-crimp glass fiber reinforced layered clay/epoxy nanocomposites
}

\author{
Emrah Bozkurt, Elçin Kaya, Metin Tanoğlu * \\ İzmir Institute of Technology, Mechanical Engineering Department, Gülbahçe Campus, 35437 Urla, İzmir, Turkey
}

Received 9 September 2006; received in revised form 14 March 2007; accepted 18 March 2007

Available online 28 March 2007

\begin{abstract}
Mechanical and thermal properties of non-crimp glass fiber reinforced clay/epoxy nanocomposites were investigated. Clay/epoxy nanocomposite systems were prepared to use as the matrix material for composite laminates. X-ray diffraction results obtained from natural and modified clays indicated that intergallery spacing of the layered clay increases with surface treatment. Tensile tests indicated that clay loading has minor effect on the tensile properties. Flexural properties of laminates were improved by clay addition due to the improved interface between glass fibers and epoxy. Differential scanning calorimetry (DSC) results showed that the modified clay particles affected the glass transition temperatures $\left(T_{\mathrm{g}}\right)$ of the nanocomposites. Incorporation of surface treated clay particles increased the dynamic mechanical properties of nanocomposite laminates. It was found that the flame resistance of composites was improved significantly by clay addition into the epoxy matrix.
\end{abstract}

(c) 2007 Elsevier Ltd. All rights reserved.

Keywords: A. Nanostructures; A. Glass fibres; A. Polymer-matrix composites (PMCs); B. Thermomechanical properties; B. Mechanical properties

\section{Introduction}

Fiber reinforced polymer matrix composites (PMCs) have been widely used in various applications, i.e., aerospace, defence, automotive, marine and sporting goods due to their high specific stiffness and strength. These materials provide high durability, design flexibility and lightweight which makes them attractive materials in these applications [1-3]. The properties of composites are significantly related to the properties of composite constituents, i.e., fiber, matrix and the interphase between them [4].

The utilization of nanoclays as fillers in polymer composites has attracted considerable attention due to the improved mechanical, thermal, flame retardant and gas barrier properties of the resulting composites. Because of the extremely high surface to volume ratios and the

\footnotetext{
* Corresponding author. Tel.: +90 23275078 06; fax: +90 23275065 05 .

E-mail address: metintanoglu@iyte.edu.tr (M. Tanoğlu).
}

nanometer size dispersion of nanoclays in polymers, they exhibit improved properties as compared to the pure polymers [2].

Clays used in preparing polymer-clay nanocomposites belong to the 2:1 layered structure. Montmorillonite (MMT) is a layered aluminoclay in the family of smectite clays. Each layer consists of two sheets of silica tetrahedra with an edge shared octahedral sheet of either alumina (aluminoclays) or magnesia (magnesium clays) [5]. These layers are hold together with a layer of charge-compensating cations such as $\mathrm{Li}^{+}, \mathrm{Na}^{+}, \mathrm{K}^{+}$, and $\mathrm{Ca}^{+}$. Generally the surface of the clay needs to be modified to improve the wettability and dispersibility of hydrophilic clay. The chargecompensating cations can be easily exchanged with surfactants including alkyl ammonium cations. The role of the alkylammonium cations in the organoclays is to lower the surface energy of the inorganic component and improve the wetting characteristics with the polymer systems $[6,7]$.

Polymer-clay nanocomposites have been synthesized with different approaches; i.e., melt intercalation, solution 
polymerization and in situ polymerization. In melt intercalation method, a thermoplastic polymer is mechanically mixed with organophilic clay at elevated temperatures. The polymer chains are then intercalated between the individual clay layers of the clay [7]. In the solution method, the polymer and the organoclay are dissolved in a polar organic solvent. The entropy gained by the desorption of solvent molecules allows the polymer chains to diffuse between the clay layers, compensating for their decrease in conformational entropy. After evaporation of the solvent, an intercalated nanocomposite is obtained $[7,8]$. In in situ polymerization technique, clay particles are dispersed in the monomer or monomer solution, and the resulting mixture is polymerized by standard polymerization methods [8].

Non-crimp fabric (NCF) reinforced composites are obtained by laminating fiber stacks which are typically made up from 2 to 4 layers of fibres stitched together through their thickness. Each layer is made up of tows of fibers placed side by side. Laminates made up with NCFs show higher compressive strength than woven fabric composites due to the lower waviness in NCF composites $[9,10]$. As another result of this waviness, laminates made up of NCF composites have higher volume fractions and strength since they do not have resin pockets unlike the woven fabrics [11]. Damage tolerance of fabric reinforced composites is also improved with the use of NCFs.

Incorporation of nano particles (clays, carbon nanotubes, etc.) in the matrix system for fiber reinforced composites has been recently studied by several groups. Kornmann et al. [12] produced glass fiber reinforced laminates with a matrix of layered clay/epoxy system and showed that flexural strength of the composites is increased due to the presence of the nano particles in the matrix. The glass fiber reinforced polymers with carbon nanotube/ epoxy matrix were manufactured by Gojny et al. [13] via resin transfer molding, and they showed that tensile properties of laminates are not influenced while the matrix dominated properties such as interlaminar shear strength and fracture toughness are increased. Subramaniyan et al. [5] fabricated composites with stitched unidirectional E-glass fibers and an epoxy vinyl ester resin via vacuum assisted wet lay-up method. They observed that addition of nanoclay increased the compressive strength of glass fiber reinforced composites. Chowdhury et al. [14] investigated the effects of nanoclay particles on flexural and thermal properties of woven carbon fiber reinforced polymer matrix composites and they showed that nanoclay addition at low concentrations increased the flexural properties as well as the thermal stability of the system. The effect of fiber direction on clay distribution in the layered clay/glass fiber/ epoxy hybrid composites was studied by Lin et al. [15]. They placed the unidirectional glass fibers parallel and perpendicular to the resin flow direction and prepared laminates using vacuum assisted resin transfer molding. The authors showed that mechanical properties were deviated with the direction of resin flow and location of glass fibers, and the composite properties were improved with the clay loading. Miyagawa et al. [16] studied the influence of biobased clay/epoxy nanocomposites as a matrix for carbon fiber composites. They found that the addition of nanoclay has no effect on the flexural strength and modulus. Although, the application of non-crimp fabrics is being increased in composite fabrication, there is limited study reporting the properties of $\mathrm{NCF}$ reinforced composites. Moreover, to our knowledge there is no study in the literature reported on the preparation and characterization of $\mathrm{NCF}$ reinforced composites with nanoclay modified matrix.

In this study, clay/epoxy nanocomposite systems were prepared to use as matrix material with non-crimp glass fabrics. Glass fabrics were impregnated with unmodified (MMT) and modified (OMMT) clay containing epoxy resins to fabricate composite laminates. The clays were intercalated with the matrix resin through insitu polymerization technique and laminates were polymerized under compression. The structure of clay and clay containing laminates were investigated by X-ray diffraction (XRD) and scanning electron microscopy (SEM). Mechanical, thermal and flammability properties of laminates manufactured with MMT and OMMT containing epoxy resin were investigated.

\section{Experimental procedure}

\subsection{Materials}

E-glass non-crimp fabrics, epoxy thermosetting resin and $\mathrm{Na}^{+}$montmorillonite clay particles were used to fabricate composite panels. As the reinforcement constituent of composites, E-glass $0^{\circ} / 90^{\circ}$ biaxial non-crimp fabrics were provided by Telateks Inc., İstanbul. DGEBA (Diglycidyl ether of bisphenol A) type epoxy resin together with an amine curing agent was used as the matrix. $\mathrm{Na}^{+}$montmorillonite (MMT) clay particles (K-10, Aldrich) with a cation exchange capacity of $120 \mathrm{meq} / 100 \mathrm{~g}$ were purchased to obtain nanocomposite matrix systems. Hexadecyltrimethylammonium chloride (HTAC, Aldrich) with $25 \mathrm{wt} \%$ sol. In water and hydrochloric acid were used for the modification of MMT particles.

\subsection{Surface modification of montmorillonite clay}

Four hundred milliliter distilled water at $80^{\circ} \mathrm{C}$ was poured into $20 \mathrm{~g}$ of clay (MMT) and stirred. Also, a solution of HTAC and hydrochloric acid $(\mathrm{HCl})$ in $100 \mathrm{ml}$ deionized water was prepared. When the acid and HTAC solution reached to $80^{\circ} \mathrm{C}$, they were mixed and stirred for $1 \mathrm{~h}$ at $80^{\circ} \mathrm{C}$. The mixture was then filtered and washed with deionized water until no chloride was detected. Residual chloride in the mixture was determined by using $\mathrm{AgNO}_{3}$. After the washing procedure is completed, the mixture was filtered and dried for three days at $75^{\circ} \mathrm{C}$. 


\subsection{Preparation of layered clay/epoxy suspension}

Layered clay/epoxy nanocomposite resin systems were prepared with 1, 3, 6, and 10\%wt of MMT and OMMT clays to use them as the matrix of fabric reinforced composites. In order to enhance the dispersion, the clay/epoxy suspensions were mechanically stirred for about $1 \mathrm{~h}$ at room temperature. After mechanical stirring, the suspension was hold in an ultrasonic bath for $20 \mathrm{~min}$ in order to further exfoliate the clay plaques within the resin. Then, a stoichiometric amount (35 parts curing agent: 100 parts epoxy by weight) of the amine curing agent was added to the suspension. Out-gassing procedure was applied by vacuuming to remove bubbles within the resin.

\subsection{Composite fabrication}

Hand lay-up technique was used to impregnate and laminate the composite structures. In this technique, glass fabrics were wetted by a thin layer of clay/epoxy suspension in a mold coated with a mold release agent. Stacking of the plies was continued until a certain thickness was obtained. After lamination procedure, composites were cured at room temperature under the pressure of $8 \mathrm{KPa}$. A post curing for $1 \mathrm{~h}$ at $80^{\circ} \mathrm{C}$ and $2 \mathrm{~h}$ at $150^{\circ} \mathrm{C}$ was applied in an oven following curing stage.

\subsection{Determination of fiber volume fraction and void content}

The fiber volume fractions of the composite panels were determined using the matrix burn out method. In this method, composite laminates were burned in a high temperature oven at about $700{ }^{\circ} \mathrm{C}$. The remaining fibers were weighed and the volume of the fibers was calculated based on the mass and the density of the fibers and the matrix. Optical microscopy on the cross sections of the laminates were performed in order to examine the alignment of non-crimp glass fabrics and to investigate the void content in the composite. An image analyzer software was used to measure areal fraction of the voids on the polished surfaces.

\subsection{Microstructural characterization}

Clay particles with and without surface modifications and composite samples obtained from laminates manufactured with MMT and OMMT with different concentrations $(0,1,3,6$ and $10 \mathrm{wt} \%)$ were analyzed by X-ray diffraction (XRD) technique using Philips X'Pert Pro diffractometer, with $\mathrm{Cu} \mathrm{K} \alpha$ radiation. Powder samples were scanned in the interval of $2 \Theta=2-12^{\circ}$ at $40 \mathrm{kV}$ and $30 \mathrm{~mA}$. Using XRD, intercalation behavior of clay particles loaded to matrix with different concentration was analyzed.

Fracture surfaces of laminates were examined with a Phillips ${ }^{\mathrm{TM}}$ scanning electron microscope (SEM) to investigate the effects of clay addition on the adhesion at the interface between glass fibers and the epoxy matrix, and the extend of clay dispersion. For this purpose, gold vapor deposition was applied onto the fractured surface of tensile specimens to have a conductive layer over the samples.

\subsection{Mechanical property characterization}

Tensile test technique, ASTM D 3039M-93 was used to determine the tensile strength and modulus of the composite laminates. The specimens were tested using Schimadzu AGI universal test machine at a crosshead speed of $2 \mathrm{~mm} / \mathrm{min}$. At least five specimens for each composition were tested. Flexural tests were performed according to ASTM D 790M-86 and the universal testing machine was used with a three point bending apparatus. Specimens were sectioned from laminates and tested with a crosshead speed of $1.7 \mathrm{~mm} / \mathrm{min}$. Five specimens from each set were tested. The apparent interlaminar shear strength (ILSS) of composite laminates was determined by short beam shear (SBS) test in accordance with ASTM D2344-84. Eight specimens from each set were tested using the test machine equipped with a three point bending apparatus with the crosshead speed of $1.3 \mathrm{~mm} / \mathrm{min}$. Fracture toughness of composites were determined according to ASTM D 504591a. Single edge notch bending (SENB) specimens were sectioned from each laminate and five samples from each set were tested with a crosshead speed of $10 \mathrm{~mm} / \mathrm{min}$.

\subsection{Thermomechanical property characterization}

Dynamic mechanical analysis (DMA) was conducted on the specimens with multi-frequency strain mode with a strain rate of $0.1 \%$ to investigate the storage modulus $\left(E^{\prime}\right)$, loss modulus $\left(E^{\prime \prime}\right)$ and glass transition temperature $\left(T_{\mathrm{g}}\right)$. While testing dual cantilever clamp were used and a heating rate of $2{ }^{\circ} \mathrm{C} / \mathrm{min}$ from 25 to $150{ }^{\circ} \mathrm{C}$ was applied. The DMA specimens were sectioned from composite laminates with the dimensions of $2.5 \mathrm{~mm}$ in thickness, $12 \mathrm{~mm}$ in width and $55 \mathrm{~mm}$ in length.

\subsection{Thermal and flammability resistance determination}

DSC analysis was conducted on the samples using a TA instrument Q10 model DSC under nitrogen atmosphere at a flow rate of $50 \mathrm{~mL} / \mathrm{min}$ in order to investigate the effect of clay loading on the glass transition temperature $\left(T_{\mathrm{g}}\right)$. To conduct DSC analysis, 5-6 mg of each specimen was weighed in an aluminum pan and placed in the instrument. The dynamic measurements were made at a constant heating rate of $10^{\circ} \mathrm{C} / \mathrm{min}$ from 25 to $200^{\circ} \mathrm{C}$. $T_{\mathrm{g}}$ of laminates manufactured with epoxy matrix containing a various concentrations of MMT and OMMT clay particles were calculated by the midpoint method.

To monitor the effect of clay loading on the flammability of the epoxy composites, flammability testing (UL94) was conducted. For comparison, the rate of burning and/or extent and time of burning of specimens containing various amount of clay was tested. Specimens were first ignited and 
the behavior of flame was observed according to ASTM D635-91. Two specimens of each laminate were tested and average extent of burning (AEB) and average time of burning (ATB) was calculated with the following equations.

$\mathrm{AEB}, \mathrm{mm}=\frac{\sum(100 \mathrm{~mm}-\text { unburned length })}{(\text { number of specimens })}$

$\mathrm{ATB}, \mathrm{mm}=\frac{\sum\left(t-t_{1}\right)}{\text { (number of specimens) }}$

where, $t$ and $t_{1}$ refers to the burning time and the time taken when the flame front reaches the $25 \mathrm{~mm}$ mark, respectively.

\section{Results and discussion}

\subsection{Fiber volume fraction and void content}

Fiber volume fraction of the composites was determined by matrix burn out method and void contents of laminates were evaluated by performing an image analysis on the optical microscopy images of each laminate cross-section. As shown in Table 1, fiber volume fractions were measured to be about $40-44 \%$ for all laminates. However, it was found that the void content of the composites increases with increase of clay content within the epoxy matrix. This is due to the increase of viscosity of the matrix of composite laminates and introduction of air bubbles from the clay particles. As it is also seen from Table 1, the increase of void content of the composites laminated with OMMT/ epoxy matrix is higher than those prepared with MMT/ epoxy matrix. The tendency of void formation is greater in OMMT/epoxy matrix due the surfactant material used for surface treatment of clay particles.

\subsection{Microstructure}

Surface treatment of montmorillonite clay particles was performed via cation exchange reaction to intercalate clay galleries. This promotes the exfoliation of clay platelets within the matrix resin. X-ray diffractograms of treated (OMMT) and untreated clay (MMT) particles are shown in Fig. 1. Surface treated OMMT particles have a d-spacing of $18.1 \AA$, while the d-spacing of MMT is $14.3 \AA$. Exchange of sodium cations by the onium cations results with the increase of the interlayer spacing of clay particles.

Fig. 2a and $b$ illustrates the XRD diffractograms of the glass fiber reinforced laminates manufactured with neat epoxy, MMT/epoxy and OMMT/epoxy nanocomposites.

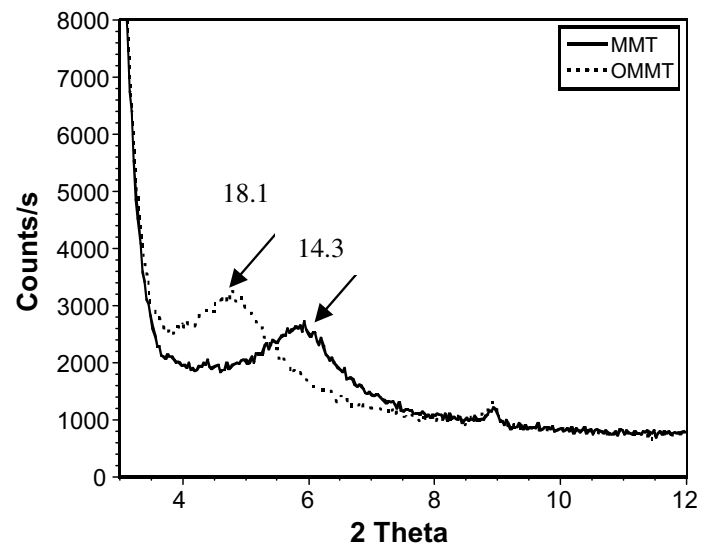

Fig. 1. X-ray diffractograms of MMT and OMMT clays.

The characteristic peaks of clays illustrated in Fig. 1 are not visible for the composites. This may be due to further intercalation of the clays during the polymerization of the resin. However, the characteristic peaks from any agglomerated clay layers may not be in the detectable level due to the presence of high fraction of glass fibers and epoxy matrix as compared to the fraction of the clays in the composites.

To reveal the agglomaration tendency of clay particles, backscattered SEM images from the fracture surfaces of neat epoxy and MMT and OMMT incorporated nanocomposite were obtained as shown in Fig. 3. As seen in Fig. 3a, smooth fractured surface are observed on neat epoxy indicating relatively brittle fracture. Fig. $3 \mathrm{~b}$ and c illustrates the microstructure of the MMT and OMMT $(10 \mathrm{wt} \%)$ where the bright features on the backscattered images correspond to clay aggregates. At high silicate concentrations, relatively higher fractions of clay agglomerations are observed from SEM images. Smaller sizes of the particles also imply better exfoliation of the silicate layers that result in improved mechanical properties. Fracture surface image (Fig. 3c) observed from the nanocomposites that in made of OMMT/epoxy indicate that organosilicate platelets are better dispersed in the epoxy matrix as compared to those for MMT/epoxy nanocomposites. This implies the surface modification and thus intercalation of silicate layers results in better dispersion of the particles within the matrix. It is obvious that larger agglomerates are formed in the structure of the material with $10 \mathrm{wt} \% \mathrm{MMT}$.

\subsection{Mechanical properties}

Tensile tests were performed on the fabric (NCF) reinforced composite laminates to observe the effect of modi-

Table 1

Fiber volume fraction and void contents of composite laminates fabricated with various type of clays

\begin{tabular}{|c|c|c|c|c|c|c|c|c|c|c|}
\hline \multirow{2}{*}{$\begin{array}{l}\text { Clay type } \\
\text { Clay concentration }\left(\mathrm{wt}^{\mathrm{o}} \%\right)\end{array}$} & \multicolumn{5}{|c|}{ MMT } & \multicolumn{5}{|c|}{ OMMT } \\
\hline & 0 & 1 & 3 & 6 & 10 & 0 & 1 & 3 & 6 & 10 \\
\hline Fiber volume fraction, $V_{\mathrm{f}}(\%)$ & 44.3 & 41.5 & 41.5 & 42.3 & 40.6 & 44.3 & 42.1 & 40.6 & 43.6 & 42.3 \\
\hline Void content $(\%)$ & 3.7 & 3.9 & 5.6 & 6.3 & 6.4 & 3.7 & 4.1 & 6.5 & 5.6 & 6.6 \\
\hline
\end{tabular}



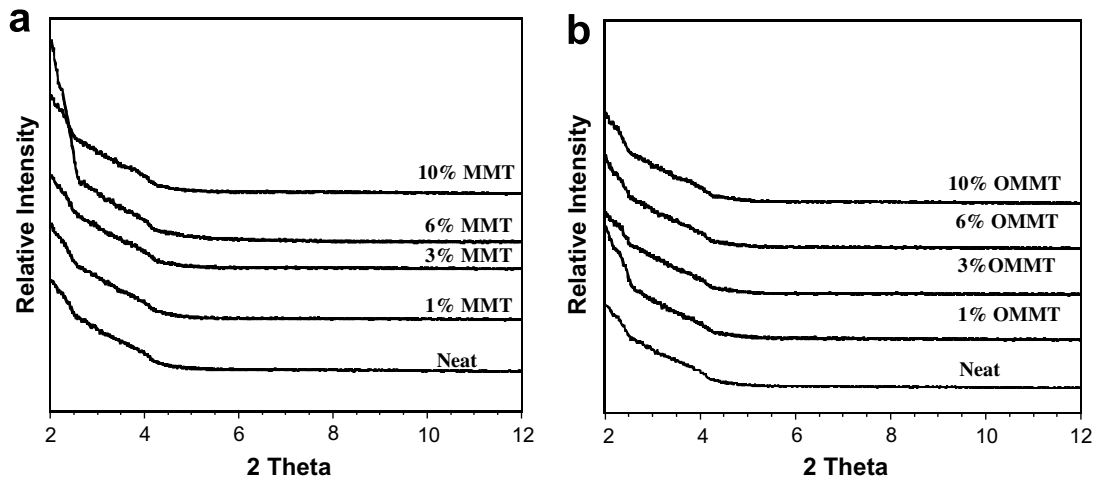

Fig. 2. X-ray diffractograms of (a) glass fiber reinforced MMT/epoxy nanocomposites and (b) glass fiber reinforced OMMT/epoxy nanocomposites.

a

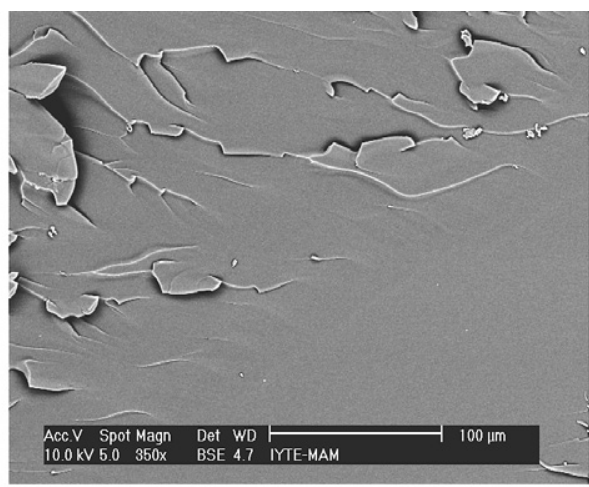

b

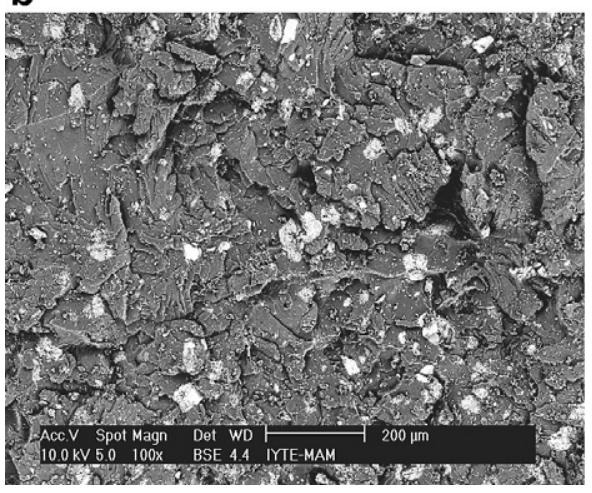

C

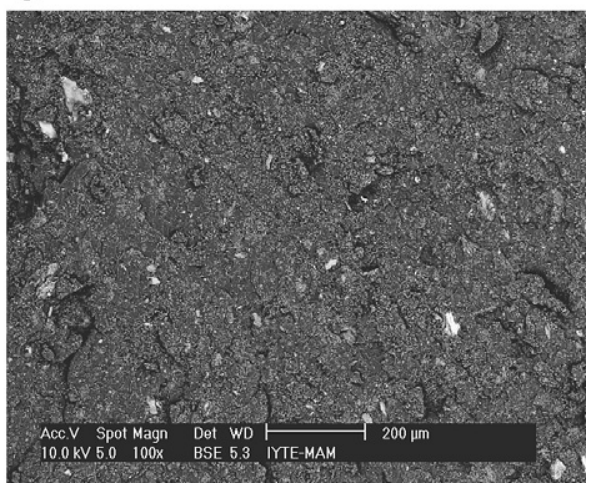

Fig. 3. SEM micrographs of fracture surfaces resulted during tensile testing (a) neat epoxy, (b) $10 \mathrm{wt} \% \mathrm{MMT} /$ Epoxy and (c) $10 \mathrm{wt} \%$ OMMT/Epoxy.

fied and unmodified clay additions to the matrix resin on the tensile behavior of the composites. Figs. 4 and 5 exhibit the tensile strength and elastic modulus of the composites. It was found that the laminates with MMT exhibit slightly higher strength values as compared to those with OMMT. However, the modulus values are almost the same up to $6 \mathrm{wt} \%$ for MMT and OMMT added composites. The tensile strength and modulus values remain almost constant by the addition of MMT and OMMT up to $6 \mathrm{wt} \%$ clay contents as compared to those fabricated without clay addition. However, further addition of MMT and OMMT reduces the strength values. On the other hand, modulus values are reduced by the addition of OMMT while they remains constant with MMT addition at $10 \mathrm{wt} \%$ clay loading. This result indicates that modifying the matrix resin of non-crimp fabric reinforced epoxy composites with clays has no significant influence on the tensile properties of the laminate due to the dominating effect of fiber reinforcement.

Figs. 6 and 7 exhibit the influence of clay loading on the flexural strength and modulus values. Flexural strength and modulus values increases with the addition of MMT and OMMT clays, up to $6 \mathrm{wt} \%$ of clay loading. Maximum improvement in flexural strength and modulus is obtained at $6 \mathrm{wt} \%$ clay content and the strength and modulus are improved by $16 \%$ and $13 \%$, respectively by the addition of nanoparticles. The improvement in the flexural strength may be related with the presence of clay layers located at the interface of the fiber and the matrix. The clay layers may enhances the interfacial properties up to some concen- 


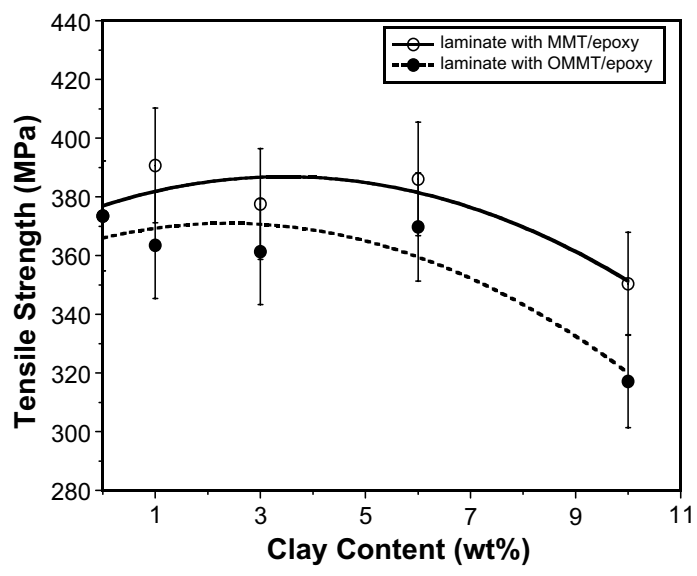

Fig. 4. Tensile strength of non-crimp glass fabric reinforced clay/epoxy nanocomposites.

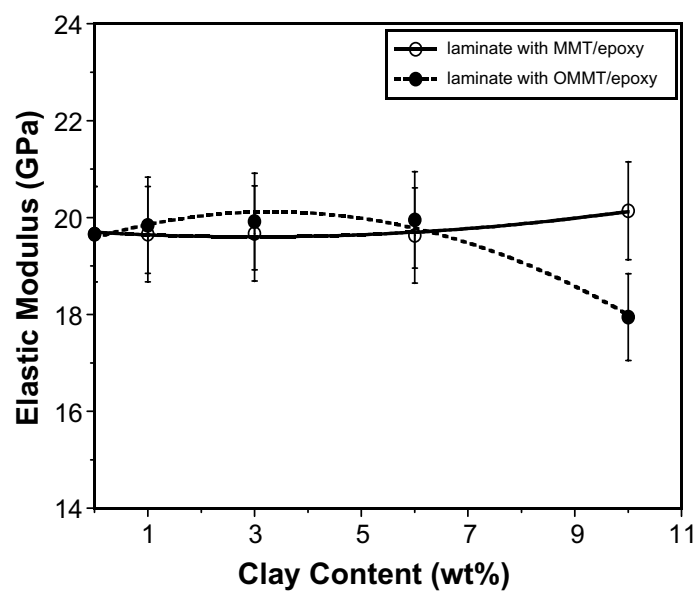

Fig. 5. Elastic modulus of non-crimp glass fabric reinforced clay/epoxy nanocomposites.

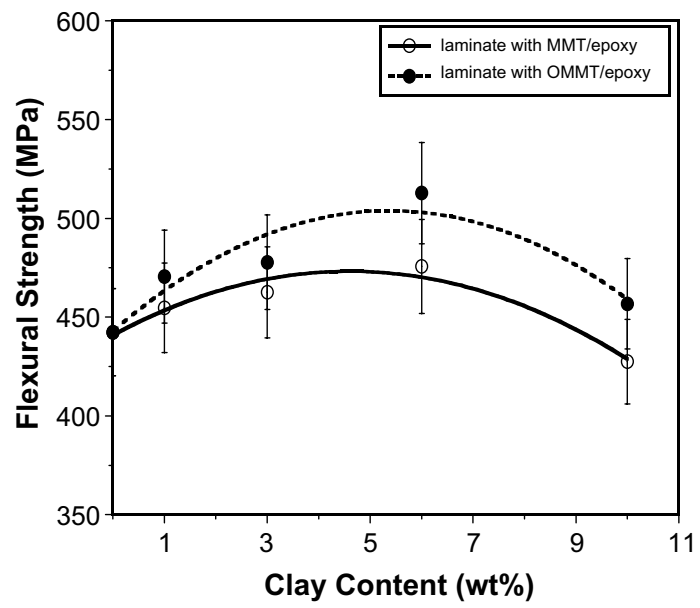

Fig. 6. Flexural strength of non-crimp glass fabric reinforced clay/epoxy nanocomposites.

trations. Figs. 8 and 9 illustrates the SEM fracture surface images of glass fabric reinforced laminates obtained from tensile test specimens prepared with neat epoxy and OMMT/epoxy suspension, respectively. As seen in

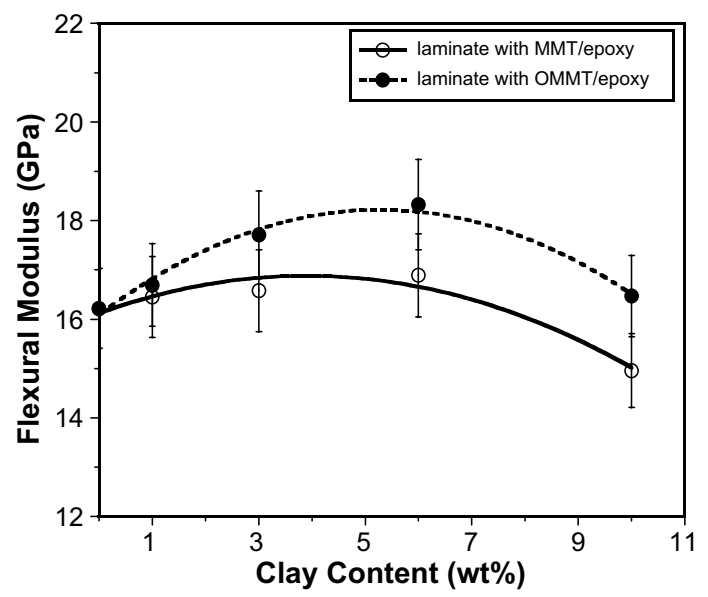

Fig. 7. Flexural modulus of non-crimp glass fabric reinforced clay/epoxy nanocomposites.

Fig. 8a and b, fracture occurs along the interface and smooth fracture surfaces are formed due to weaker interfacial debonding in laminates without clay addition. In contrast, in the case of composites laminated with clay containing epoxy matrix, it is evident that fracture mechanisms are altered due to the presence of clays. The fracture modes indicate that a stronger interface is formed in these composites.

Short beam shear test was applied to the laminates to determine the interlaminar shear strength (ILSS) of composites prepared with different clay loadings. Apparent ILSS of fabric reinforced composites with neat epoxy matrix was measured as $32.7 \mathrm{MPa}$. With the addition of clay, ILSS of laminates decreases slightly and the reduction is greater in the case of OMMT particles addition (Fig. 10). The reduction may be related with the formation of voids in the matrix which is generally located at the interlaminar region of composites. The tendency of void formation is higher in OMMT added composites as compared to MMT added ones, as given in Table 1.

Fracture toughness of laminates containing various concentrations of MMT and OMMT particles were obtained by loading the SENB specimens along in-plane directions. Fracture toughness of composites laminated with neat epoxy was measured as $2.8 \mathrm{MPa} \mathrm{m}^{1 / 2}$. With the addition of OMMT $(10 \mathrm{wt} \%)$ particles to the matrix, fracture toughness of laminates increases by $5 \%$, as shown in Fig. 11. However, the presence of MMT particles slightly reduces $K_{\text {IC }}$ values. As a result of loadings along the in-plane directions, fiber-matrix debonding, fiber pull-out; fiber and matrix fracture mechanisms were observed to occur in laminates. A better dispersion and intercalation of OMMT particles may be related with the higher $K_{\mathrm{IC}}$ values measured from composites prepared with OMMT/epoxy matrix. The reduction in $K_{\mathrm{IC}}$ values with the addition of MMT particles may be related to the higher amount of agglomerates. 
a

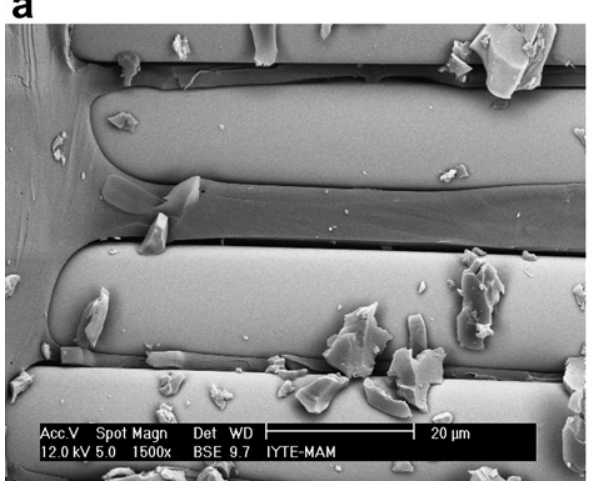

b

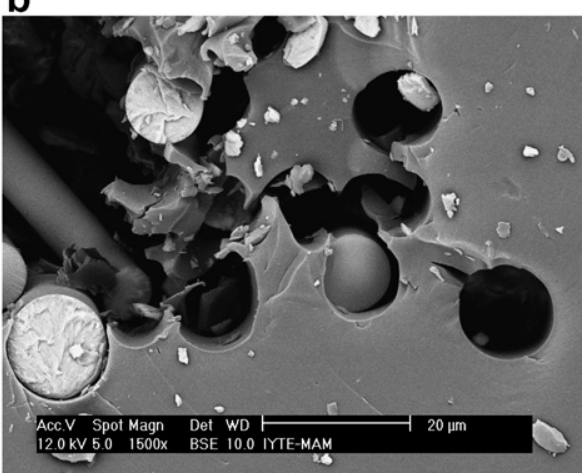

Fig. 8. SEM fracture surface images of glass fiber/epoxy composites without clay addition $(\mathrm{a}, \mathrm{b})$.

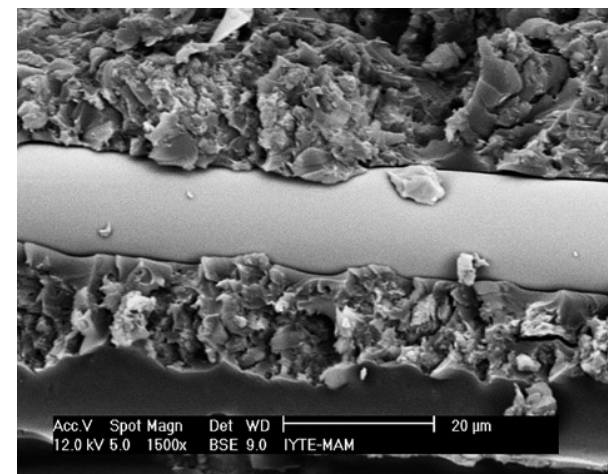

Fig. 9. SEM fracture surface images of glass fiber/epoxy composites with $10 \mathrm{wt} \%$ clay addition.

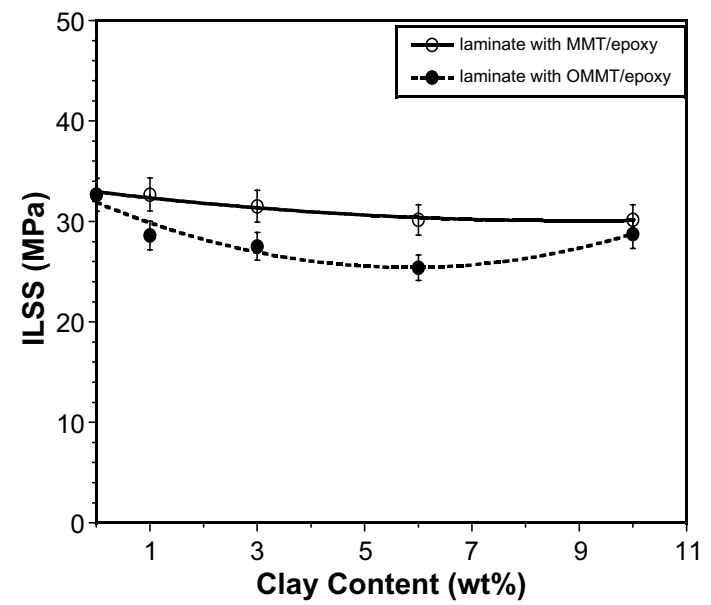

Fig. 10. Interlaminar shear strength (ILSS) of fabric reinforced clay/ epoxy nanocomposites.

\subsection{Thermomechanical properties}

Fig. 12 exhibit the influence of clay loading on the storage modulus values as a function of clay loading. With the addition of clay particles, the storage modulus of laminates increases up to $6 \mathrm{wt} \%$ clay content. As a result of incorporation of $6 \mathrm{wt} \%$ of MMT and OMMT particles into the matrix, an increase of about $57 \%$ and $51 \%$ in storage mod-

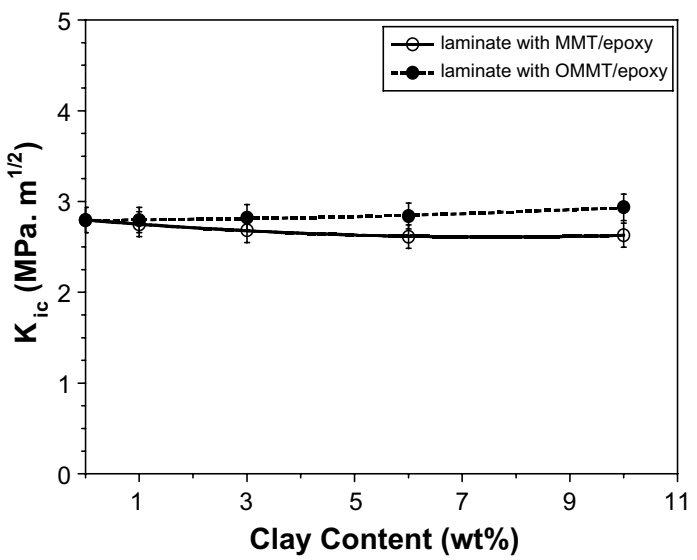

Fig. 11. Fracture toughness $\left(K_{\mathrm{IC}}\right)$ of fabric reinforced clay/epoxy nanocomposites.

ulus was obtained, respectively. The loss modulus of composites prepared without clay addition was measured to be $1.02 \mathrm{GPa}$ as shown in Fig. 13. The addition of $6 \mathrm{wt} \%$ of MMT and OMMT to the matrix increases the loss modulus of composites to 1.9 and $1.8 \mathrm{GPa}$, respectively. In general, addition of clay particles increases the storage

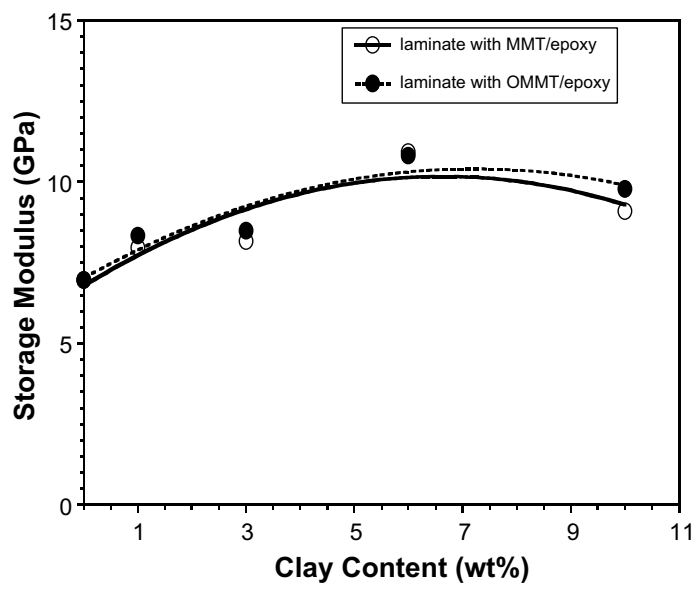

Fig. 12. Storage modulus of non-crimp fabric reinforced clay/epoxy nanocomposites. 


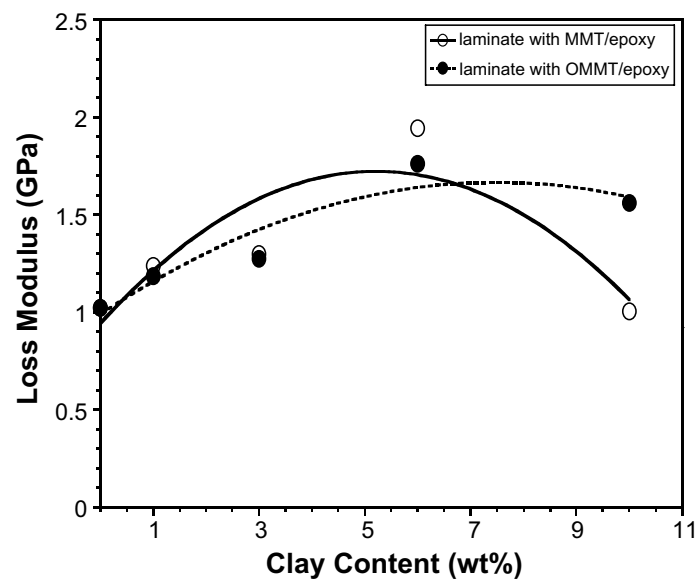

Fig. 13. Loss modulus of non-crimp fabric reinforced clay/epoxy nanocomposites.

and loss modulus of composites by restricting the molecule motions.

Fig. 14 shows the effect of clay loading on the glass transition temperature $\left(T_{\mathrm{g}}\right)$ of laminates obtained from DMA. $T_{\mathrm{g}}$ of composites prepared with neat epoxy was measured as $81.9^{\circ} \mathrm{C}$. Addition of MMT particles slightly increases the $T_{\mathrm{g}}$ of the laminates by $3 \%$ up to the concentration of $3 \mathrm{wt} \%$ and further addition reduces the $T_{\mathrm{g}}$. The reduction is $6 \%$ (from $81.9^{\circ} \mathrm{C}$ to $76.8^{\circ} \mathrm{C}$ ) with the addition of $10 \mathrm{wt} \%$ MMT. This may be related with the void content and the agglomerated structure of unmodified silicate layers at higher clay concentration. In contrast, incorporation of OMMT particles increased the $T_{\mathrm{g}}$ of laminates by $5 \%$ (from $81.9^{\circ} \mathrm{C}$ to $86.2^{\circ} \mathrm{C}$ ) with the addition of $10 \mathrm{wt} \%$ OMMT. This improvement is due to the restricted mobility of polymer molecules that was similarly observed in DSC analysis.

\subsection{Thermal properties}

The $T_{\mathrm{g}}$ of fabric reinforced clay/epoxy nanocomposites were also measured from DSC analysis and the effect of

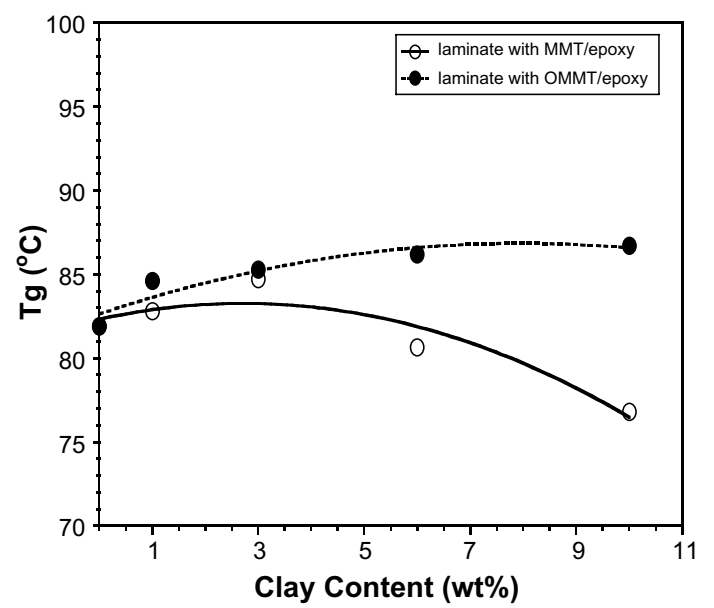

Fig. 14. $T_{\mathrm{g}}$ of non-crimp glass fabric reinforced clay/epoxy nanocomposites obtained by DMA nanocomposites.

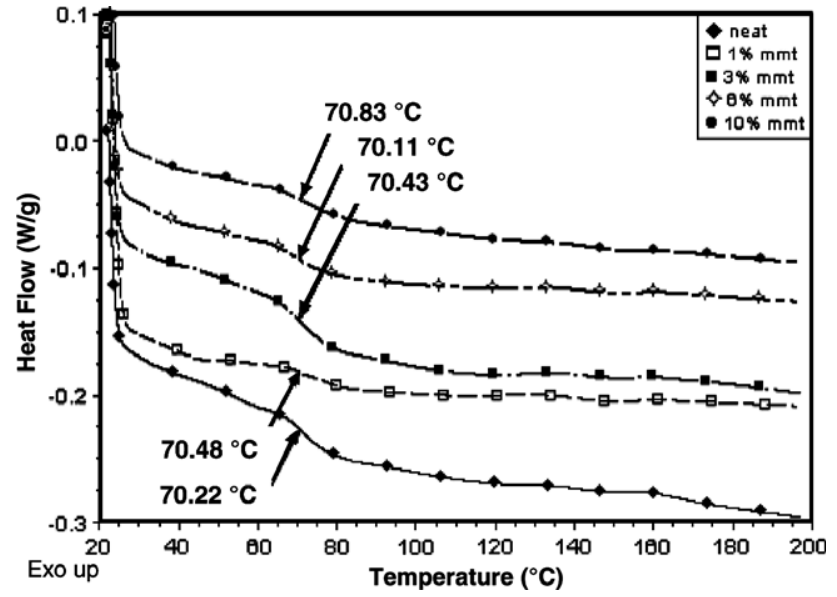

Fig. 15. DSC thermographs of fabric reinforced MMT/epoxy nanocomposites.

clay content on the $T_{\mathrm{g}}$ values of laminates are illustrated in Figs. 15 and 16.

Addition of MMT particles to the epoxy matrix has almost no effect on the $T_{\mathrm{g}}$ values as shown in Fig. 15 and the $T_{\mathrm{g}}$ of the laminates were determined as $70^{\circ} \mathrm{C}$. Fig. 16 reveals an increase of $T_{\mathrm{g}}$ of the composites with OMMT/ epoxy matrix. $T_{\mathrm{g}}$ of the laminates increases by $7 \%$ up to $6 \mathrm{wt} \%$ OMMT clay content. However, a reduction of $T_{\mathrm{g}}$ was observed with the addition of higher contents $(10 \mathrm{wt} \%$ OMMT). Surfactant used for the surface treatment of clays may have a plasticizing effect on polymer and the excess surfactant at high concentrations may dominate to decrease the $T_{\mathrm{g}}$ values. Although, the $T_{\mathrm{g}}$ values obtained from DSC and DMA were not same, because of the sensitivity difference between these methods or due to variability in the material due to mixing, and/or thermal gradients during cutting. The tendency of the change of the $T_{\mathrm{g}}$ with the MMT and OMMT particles are almost the same with DSC and DMA measurements.

(UL94) and the results are shown in Fig. 17a and b. As it can be clearly seen in figures, addition of clay significantly

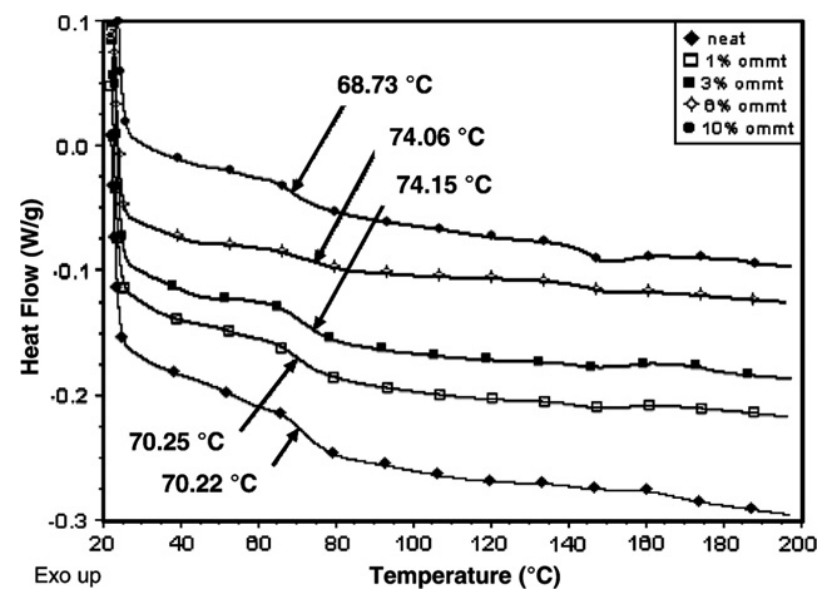

Fig. 16. DSC thermographs of fabric reinforced OMMT/epoxy nanocomposites. 

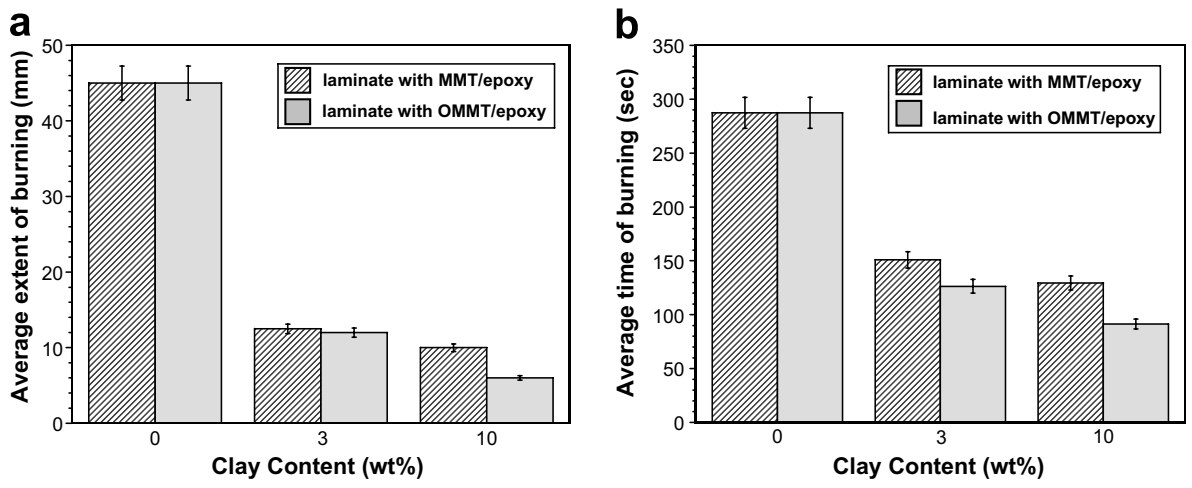

Fig. 17. Influence of clay loading on the flammability of the fabric reinforced clay/epoxy nanocomposites on (a) extent of burning and (b) time of burning.

reduced the flammability of polymer composites and average extend of burning and average time of burning is reduced by $55 \%$ and $77 \%$ due to the addition of $10 \mathrm{wt} \%$ MMT into epoxy. This improvement is even higher with surface treated clay (OMMT) due to its better dispersion in the polymer matrix.

\section{Conclusions}

Clay/epoxy nanocomposites were synthesied with different concentrations of MMT and OMMT clay through insitu polymerization and were succefully used as matrix resin for non-crimp glass fabric reinforced polymer composites. X-ray analysis of surface treated and untreated clays reveal that the modification of clay increased the $d$ spacing of clay layers that ease the dispersion of clay particles in the matrix. The tensile strength and modulus values remains almost constant by the addition of MMT and OMMT up to $6 \mathrm{wt} \%$ clay contents as compared to those fabricated without clay addition. However, further addition of MMT and OMMT reduced the strength values. On the other hand, tensile modulus values are reduced by the addition of OMMT while they remained constant with MMT addition at $10 \mathrm{wt} \%$ clay loading. Flexural strength and modulus values are increased with the addition of MMT and OMMT, up to $6 \mathrm{wt} \%$ of clay loading. Maximum improvement in flexural strength and modulus is obtained at $6 \mathrm{wt} \%$ clay content and by the addition of nanoparticulates the flexural strength and modulus are improved by $16 \%$ and $13 \%$, respectively. Apparent interlaminar shear strength (ILSS) of fabric reinforced composites with neat epoxy matrix was measured as $32.7 \mathrm{MPa}$. With the addition of clay, ILSS of laminates decreased slightly and the reduction is greater in the case of OMMT particles addition. With the addition of OMMT (10 $\mathrm{wt} \%)$ particles to the matrix, fracture toughness of laminates increased by $5 \%$. However, the presence of MMT particles slightly reduced the $K_{\mathrm{IC}}$ values. The fracture surface examinations revealed that, in the case of composites laminated with clay containing epoxy matrix fracture mechanisms are altered due to presence of clays. Addition of MMT particles to the matrix has almost no effect on the $T_{\mathrm{g}}$ values and $T_{\mathrm{g}}$ of the laminates increased by $7 \%$ up to $6 \mathrm{wt} \%$
OMMT clay content. According to DMA results, addition of clay particles to the matrix increased the storage and loss modulus of composites and $T_{\mathrm{g}}$ of composites increased with the addition of OMMT particles. Addition of clay significantly reduced the flammability of polymer composites. The average extend of burning and average time of burning is reduced by $55 \%$ and $77 \%$, respectively due to the addition of $10 \mathrm{wt} \%$ MMT into epoxy. This improvement was even higher with surface treated clay (OMMT) due to its better dispersion in the polymer matrix.

\section{Acknowledgements}

The authors gratefully acknowledge The Scientific and Technical Research Council of Turkey (TÜBITAKMAG) for the financial support to $104 \mathrm{M} 365$ project.

\section{References}

[1] Tanoğlu M, Seyhan AT. Investigating the effects of a polyester preforming binder on the mechanical and ballistic performance of Eglass fiber reinforced polyester composites. Int J Adhes Adhesi 2003;23:1-8.

[2] Jinlian H, Yi L, Xueming S. Study on void formation in multi-layer woven fabrics. Compos A 2004;35:595-603.

[3] Tarim N, Findik F, Uzun H. Ballistic impact performance of composite structures. Compos Struct 2002;56:13-20.

[4] Shahid N, Villate RG, Baron AR. Chemically functionalized alumina nanoparticle effect on carbon fiber/epoxy composites. Compos Sci Technol 2005;27:1123-31.

[5] Subramaniyan AK, Sun CT. Enhancing compressive strength of unidirectional polymeric composites using nanoclay. Compos A 2006;12:1454-62.

[6] Giannelis EP. Polymer layered clay nanocomposites: synthesis, properties and applications. Appl Organometal Chem 1998;12:675-80.

[7] Ahmadi SJ, Huang YD, Li W. Synthetic routes, properties and future applications of polymer-layered clay nanocomposites. J Mater Sci 2004;39:1919-25.

[8] Qutubuddın S, Fu X. Nano-surface chemistry. Marcel Dekker Incorp.; 2001. p. 653-671.

[9] Drapier S, Wisnom MR. F.E. Investigation of the non-crimp fabrics compressive and interlaminar behaviors. Compos Sci Technol 1999;56:1287-97.

[10] Zhao LG, Warrior NA, Long AC. Finite element modeling of damage progression in non-crimp fabric reinforced composites. Compos Sci Technol 2006;66:36-50. 
[11] Adden S, Horst P. Damage propagation in non-crimp fabrics under bi-axial static and fatigue loading. Compos Sci Technol 2006;66:626-63.

[12] Kornmann X, Rees M, Thomann Y, Necola A, Barbezat, Thoman R. Epoxy-layered clay nanocomposites as a matrix in glass fibrereinforced composites. Compos Sci Technol 2005;65:2259-68.

[13] Gojny FH, Wichmann MHG, Fiedler B, Bauhofer W, Schulte K. Influence of nano-modification on mechanical and electrical properties of conventional fibre-reinforced composites. Compos A 2005;36:1525-35.
[14] Chowdury FH, Hosur MV, Jeelani S. Studies on the flexural and thermomechanical properties of woven carbon/nanoclay- epoxy laminates. Mater Sci Eng A 2006;421:298-306.

[15] Lin L, Lee J, Hong C, Yoo G, Advani SG. Preparation and characterization of layered clay/glass fiber/epoxy hybrid nanocomposites via vacuum-assisted resin transfer molding (VARTM). Compos Sci Technol 2006;66:2116-25.

[16] Miyagawa H, Jurek RJ, Mohanty AK, Misra M, Drzal LT. Biobased epoxy/clay nanocomposites as a new matrix for CRFP. Compos A 2006;37:54-62. 